\title{
Management and exploitation of direct normal irradiance resources for concentrating solar collectors: Algeria as a case study
}

\author{
Mohamed Salah Mecibah • Taqiy Eddine Boukelia • \\ Nour Eddine Benyahia
}

Received: 14 July 2014/ Accepted: 29 October 2014/Published online: 12 November 2014

(C) The Author(s) 2014. This article is published with open access at Springerlink.com

\begin{abstract}
The use of concentrating solar collectors which are used in solar thermal power plant and concentrated photovoltaic systems implies that these systems only work with the direct normal irradiance (DNI). Unfortunately, DNI ground-based measurements are rarely available at the location of interest, this lack of DNI data contrasts with the availability of global and diffuse horizontal irradiance data (GHI, DHI). Nowadays, several spatial databases that estimate DNI have been developed; however, these databases present uncertainty and provide different values of DNI. In this present study, a proposed methodology for estimating the hourly, monthly mean daily, monthly and annual direct normal irradiance DNI in the presence or absence of measured global and diffuse horizontal irradiances. When applying the proposed method for calculation of DNI for three Algerian ground stations (Algiers, Ghardaia, and Tamanrasset), we obtained better performances than those of the five spatial databases' data, especially for the monthly values. The methodology seems to give a very appropriate way for management and exploitation of DNI resources for the design and analysis of concentrating photovoltaic and thermal systems; and can be applicable to other worldwide locations using empirical equations with new correlation coefficients for estimating direct normal irradiance.
\end{abstract}

M. S. Mecibah · T. E. Boukelia ( $\square)$

Laboratory of Mechanics, Mechanical Engineering Department, Faculty of Technology Sciences, University of Constantine 1, 25000 Constantine, Algeria

e-mail: taqy25000@hotmail.com

\section{N. E. Benyahia}

Applied Energetic and Pollution Laboratory, Mechanical Engineering Department, Faculty of Technology Sciences, University of Constantine 1, 25000 Constantine, Algeria
Keywords Direct normal irradiance - Global irradiance · Diffuse irradiance $\cdot$ Spatial database $\cdot$ Statistical parameter
Abbreviations
CSP Concentrating solar thermal power systems
$\mathrm{CPV}$ Concentrating solar photovoltaic power systems
DNI Direct normal irradiance
GHI Global solar irradiance on a horizontal surface data
DHI Diffuse solar irradiance on a horizontal surface data
NMO National Meteorological Office
WMO World Meteorological Organization
List of symbols
$\delta \quad$ Declination angle $\left({ }^{\circ}\right)$
$\omega_{\mathrm{s}} \quad$ Sunrise hour angle $\left({ }^{\circ}\right)$
$H_{0} \quad$ Monthly mean daily extraterrestrial solar irradiance on a horizontal surface $\left(\mathrm{kW} / \mathrm{m}^{2}\right)$
$d_{\mathrm{r}} \quad$ Relative earth-sun distance
$S_{0} \quad$ Maximum possible sunshine duration (day length) (h)
$J \quad$ Number of day in the year
$\varphi \quad$ Latitude $\left({ }^{\circ}\right)$
$I_{\mathrm{sc}} \quad$ Solar constant $\left(\mathrm{kW} / \mathrm{m}^{2}\right)$
$S \quad$ Sunshine duration (h)
$H_{\mathrm{G}} \quad$ Monthly mean daily global solar irradiance on a horizontal surface $\left(\mathrm{kWh} / \mathrm{m}^{2}\right)$
$H_{\mathrm{D}} \quad$ Monthly mean daily diffuse solar irradiance on a horizontal surface $\left(\mathrm{kW} / \mathrm{m}^{2}\right)$
$I_{\mathrm{G}} \quad$ Monthly mean hourly global solar irradiance on a horizontal surface $\left(\mathrm{kW} / \mathrm{m}^{2}\right)$
$I_{\mathrm{D}} \quad$ Monthly mean hourly diffuse solar irradiance on a horizontal surface $\left(\mathrm{kW} / \mathrm{m}^{2}\right)$ 
$I_{\mathrm{BH}} \quad$ Monthly mean hourly direct solar irradiance on a horizontal surface $\left(\mathrm{kW} / \mathrm{m}^{2}\right)$

$I_{\mathrm{BN}} \quad$ Monthly mean hourly direct normal irradiance (kW/ $\mathrm{m}^{2}$ )

$H_{\mathrm{BN}}$ Monthly mean daily direct normal irradiance $(\mathrm{kWh} /$ $\mathrm{m}^{2}$ )

$\bar{H}_{\text {BN }} \quad$ Monthly direct normal irradiance $\left(\mathrm{kW} / \mathrm{m}^{2}\right)$

$\overline{\bar{H}}_{\mathrm{BN}} \quad$ Annual direct normal irradiance $\left(\mathrm{kW} / \mathrm{m}^{2}\right)$

\section{Introduction}

The quality of life and safeness of the present and future are strongly intertwined with the availability of energy sources and the environmental protection factors. There is no doubt that the available fossil energies would not disappear soon; nevertheless, the era of abundance and cheap energy will not last long; we will have to consider alternate sources of energy, and it is clear that renewable energy is linked to environmental issues [1,2].

In order to use the enormous source of renewable energies, Algeria has created a green momentum by launching an ambitious program to develop renewable energies (RES) and promote energy efficiency. This program leans on a strategy focused on developing and expanding the use of inexhaustible resources, such as solar, biomass, geothermal, wind, and hydropower, energies in order to diversify energy sources and to prepare Algeria for tomorrow [3].

The strategic choice of this program is motivated by the huge potential of solar energy; this energy is the major focus of the program of which the concentrating solar thermal power (CSP) and photovoltaic systems (CPV) constitute an essential part. Solar should achieve more than $37 \%$ of national electricity production by 2030 [4].

The knowledge of solar radiation data at any location is essential for the selection, design, and economic evaluation of concentrating solar power plants. The use of concentrating solar collectors which are used in solar thermal power plant and concentrated photovoltaic systems implies that these systems only work with the direct normal irradiance (DNI), which is irradiance normal to sun minus diffuse solar radiation from atmosphere, clouds, and ground [5]. In particular, the intensity and distribution of DNI are dominating factors for the design and performance of CSP and CPV plants.

The DNI data can be measured by pyrheliometers which are mounted on an instrument that tracks the sun or by rotating shadow band pyranometers [6]. The pyrheliometers and tracking systems have a high investment cost and require daily monitoring to ensure the accuracy of the data. Unfortunately, DNI ground-based measurements are rarely available at the location of interest because the reasons of high cost and maintenance problems especially for developing countries like Algeria. This lack of DNI data contrasts with the availability of global and diffuse horizontal irradiance data (GHI, DHI), which are easy to find or measure, cause the instrumentation used for collection of GHI and DHI data can be an order of magnitude less expensive, and are not as labor intensive [7].

Nowadays, several spatial databases provide DNI values developed by different approaches, various spatial and temporal coverages, and different time intervals and space resolutions, even for those exploiting satellite data [8]. These databases are available as a result of international and national projects, such as NASA-SSE [9] by the Atmospheric Science Data Center, which is an example of public domain data source, SoDa [10] by Mines ParisTech that offer free data to some extent only, and Meteonorm [11] by Meteotest as a commercial data source. These databases contain different kinds of solar data [12]:

- Measured data, with different quality measuring and from different years.

- Interpolating data, which come from grids of different densities in the input data and from different years.

- Estimation data, that need to take into account the model features (years of data and images used in the development), the characteristics of images (resolution and geometry), and the time periods of the used data.

However, these databases show different values of various sources of uncertainties because they are using different kinds of input data and different procedures to calculate DNI data, in addition to the lack of continuity in the measured data that are limited to just a few number of ground stations [13].

Solanki and Sangani [14] developed a new method based on empirical relations and used elevation angle constant for a given location in the world for estimation of direct normal irradiance. WhilePérez-Higueras et al. [13] presented a simplified method for calculating direct normal irradiation that use only latitude and global horizontal irradiation as input data.

In this study, a simplified methodology for estimation of the hourly, monthly mean daily, and annual direct normal irradiance DNI data in the presence or absence of measured global and diffuse horizontal irradiances (GHI, DHI) is carried out first. In the second part, the data of the modeled DNI in addition to five solar databases available for Algeria: NASA-SSE [9], Solar-Med-Atlas [15], SoDa (HelioClim 1) [10], SolarGIS [16], and Meteonorm [11] are validating their uncertainties in comparison with the measured data of three ground stations in Algeria (Algiers, Ghardaia, and Tamanrasset). This contribution's goal is to evaluate the accuracy of the hourly, monthly mean, and the 
Fig. 1 Location of the three ground stations considered on the map

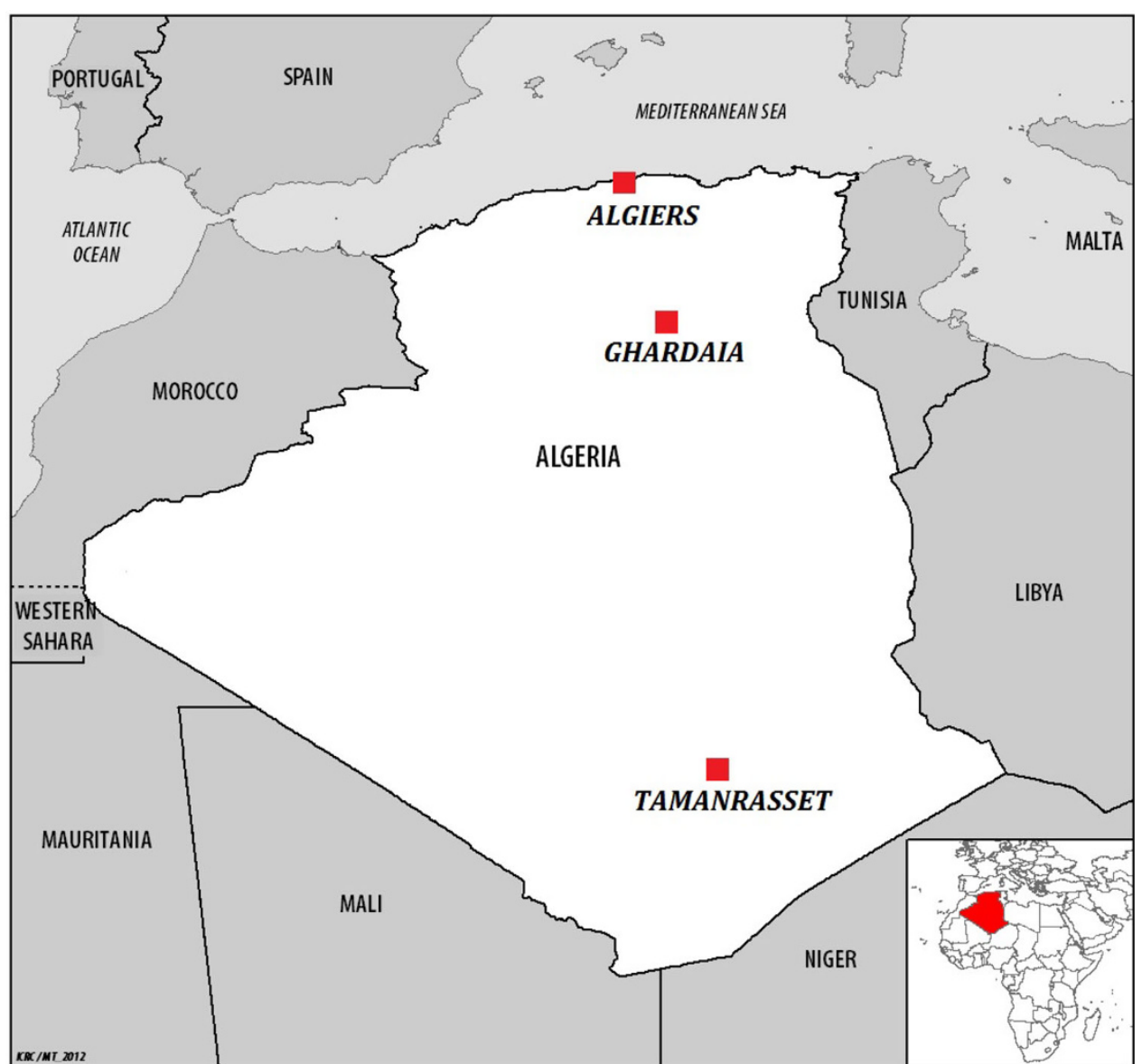

Table 1 Geographic and climatic characteristics of the studied stations

\begin{tabular}{lllrl}
\hline Sites & $\begin{array}{l}\text { Latitude } \\
\left(\mathrm{N}^{\circ}\right)\end{array}$ & $\begin{array}{l}\text { Longitude } \\
\left(\mathrm{E}^{\circ}\right)\end{array}$ & $\begin{array}{l}\text { Latitude } \\
(\mathrm{m})\end{array}$ & Climate \\
\hline Algiers & 36.43 & 3.15 & 25 & Mediterranean \\
Ghardaia & 32.36 & 3.81 & 450 & Desert arid \\
Tamanrasset & 22.87 & 5.51 & 1,377 & Desert arid \\
\hline
\end{tabular}

annual sum of DNI in order to choose the best data for CSP and CPV application in Algeria.

\section{Data and methodology}

Measured data

In order to analyze the uncertainties of the modeled and spatial databases that estimate the values of DNI, the measured direct normal irradiance data were collected in just three Algerian ground meteorological stations (Algiers, Ghardaia, and Tamanrasset) with different climatic conditions (Fig. 1), because the reliable and continuous DNI measurements are scarce and rare. Although the study is focused only on DNI data, measured GHI and DHI data are required as inputs for the modeled DNI data. Table 1 summarizes the geographic locations for each station.

The solar radiation data of Algiers were collected with the radiometric station called "Chems", installed at the Center for the Renewable Energy Development of Bouzaréah, the station essentially consists of [17]:

- Three EKO pyranometer and a pyrheliometer with a sun tracker for measuring global, diffuse, and direct normal radiations.

- A data Logger "Micrologger CR 3000" with data acquisition system for reading measurements every 5 min since 2011 to the present day.

While, the measured solar radiation of Ghardaia was collected by the radiometric station installed at the Unit of Applied Research in Renewable Energy of Ghardaia. The station has two main parts:

- A fixed part consisting of two EKO pyranometer for the measurements of global and diffuse horizontal solar radiations. 
- A second moving part with EKO pyrheliometer pointed at the sun disk for measuring direct normal irradiance.

In addition to a data logger and a CAMPBELL SCIENTIFIC CR10X data acquisition system was installed, for reading measurements every $5 \mathrm{~min}$ since 2004 to the present day.

For Tamanrasset station, the radiation measurements began in September 1994, as a part of collaboration between the National Meteorological Office (NMO) and the World Meteorological Organization (WMO). The station is included in a high accuracy network with CR23X Data logger with 3 min step, and by using two PSP pyranometers for the measurement of global and diffuse solar radiation and a NIP pyrheliometer for direct normal irradiance.

DNI satellite-derived databases

In general, satellite-derived databases are characterized by several criteria, e.g., [18, 19] input and output data, spatial and time resolution, period of time, methods for the computation, and the algorithm used for the simulation.

The databases used in this study described above have been the next:

- NASA-SSE (Surface Meteorology and Solar Energy): it combines the results from GEWEX/SRB3 and ISCCP projects with NCAR reanalysis products (1983-2005), and provides monthly and annual (global, diffuse horizontal, and direct normal irradiations values). Its web page is (http://eosweb.larc.nasa.gov/sse/) in a version that is more applicable to renewable energy technology with the data accuracy and its methodology.

- Solar-Med-Atlas (Solar Atlas for the Mediterranean): it has high-resolution (1 km), and long-term coverage of at least 20 years of data (1991-2010). The free access to the data includes historical annual and monthly averages of the global horizontal and direct normal irradiance data for the southern and eastern Mediterranean regions. The current database can be accessed at http://www.solar-med-atlas.com.

- HelioClim1 (SoDa): these data are modeled from Meteosat imagery covering Europe, Africa, the Mediterranean Basin, the Atlantic Ocean, and part of the Indian Ocean, with $20-\mathrm{km}$ spatial resolution and a period of record (1985-2005). The databases of HelioClim1 can be accessed through the SoDa service in the page http://www.soda-is.com/eng/index.html.

- SolarGIS: it is a geographic information system (GIS) that uses a new model for high-performance calculation of global and direct irradiances for the regions covered by Meteosat MSG (Europe, Africa, and the Middle East) for a period (2004-2010). Its web page is solargis.info/.

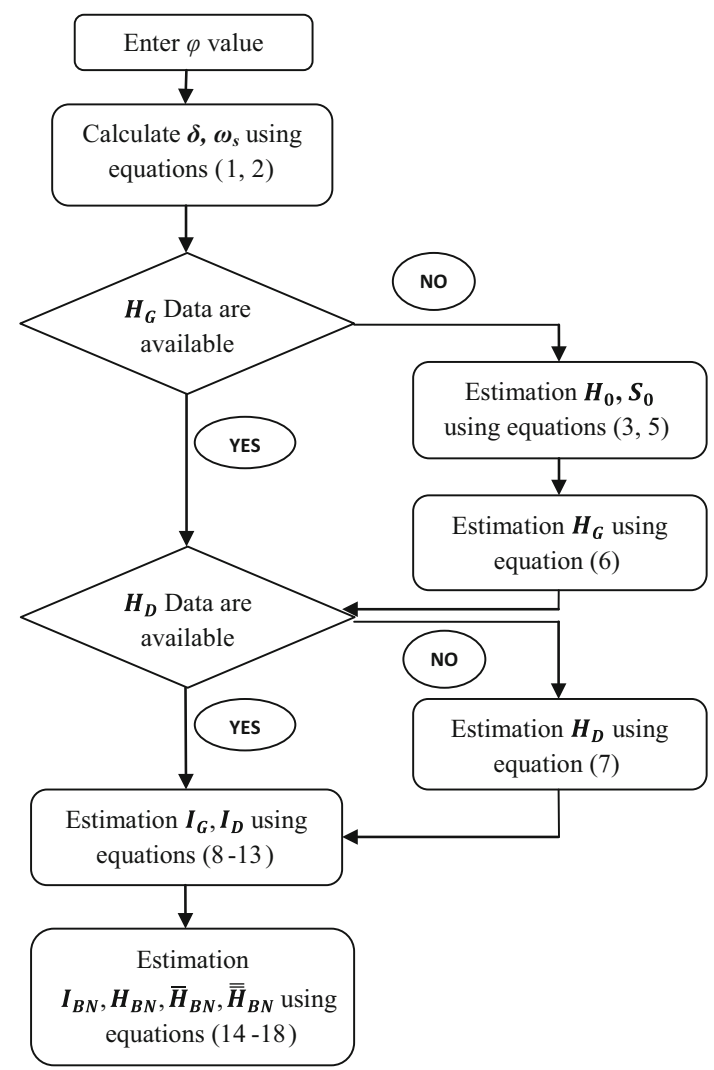

Fig. 2 Chart of the proposed methodology

- Meteonorm: it is a global database that is developed by interpolation of the observed data of 7,756 ground stations (1981-2000) with the support of satellite images (2003-2005) of MSG and four other geostationary satellites. Its web page is http://www.meteonorm.com.

DNI estimation procedure

The procedure that calculates DNI values in the presence or absence of measured global and diffuse horizontal irradiances is presented in Fig. 2, using the following steps:

I. Estimation of solar declination and sunrise hour angles [20]

$$
\begin{aligned}
& \delta=23.45 \sin \left[\frac{(J+284) 360}{365}\right] \\
& \omega_{\mathrm{s}}=\arccos [-\tan (\varphi) \tan (\delta)]
\end{aligned}
$$

II. Estimation of monthly mean daily extraterrestrial irradiance $H_{0}$, and maximum possible sunshine duration $S_{0}$ can be calculated from the following equations [20]:

$$
\begin{aligned}
& H_{0}=\left(\frac{24 \times 3600 \times I_{\mathrm{sc}}}{\pi}\right) d_{\mathrm{r}} \\
& {\left[\cos (\varphi) \cos (\delta) \sin \left(\omega_{\mathrm{s}}\right)+\frac{\pi \omega_{\mathrm{s}}}{180} \sin (\varphi) \sin (\delta)\right]}
\end{aligned}
$$




$$
\begin{aligned}
& d_{\mathrm{r}}=1+0.333 \cos \left(\frac{360}{365} \mathrm{~J}\right) \\
& S_{0}=\frac{2 \omega_{\mathrm{s}}}{15},
\end{aligned}
$$

where $d_{\mathrm{r}}$ is the relative earth-sun distance, $\delta$ is the solar declination, $\omega_{\mathrm{s}}$ is the sunrise hour angle, $\varphi$ is the latitude, and $J$ is the number of days in the year that is taken from Table 1.6.1 [20].

III. Estimation of monthly mean daily global irradiance on horizontal surface $H_{\mathrm{G}}$ [21]

$$
\begin{aligned}
H_{\mathrm{G}}= & \left(0.57089+0.01028\left(\frac{S}{S_{0}}\right)-0.00005\left(\frac{S}{S_{0}}\right)^{2}\right) \\
& \times H_{0} .
\end{aligned}
$$

IV. Estimation of monthly mean daily diffuse irradiance on horizontal surface $H_{\mathrm{D}}$ [22]

$$
\begin{aligned}
H_{\mathrm{D}}= & \left(0.337-0.068\left(\frac{H_{\mathrm{G}}}{H_{0}}\right)+0.025\left(\frac{H_{\mathrm{G}}}{H_{0}}\right)^{2}\right. \\
& \left.-0.002\left(\frac{H_{\mathrm{G}}}{H_{0}}\right)^{3}\right) \times H_{\mathrm{G}} .
\end{aligned}
$$

V. Estimation of monthly mean hourly global solar irradiance on a horizontal surface [23]

$$
\begin{aligned}
I_{\mathrm{G}}= & r_{\mathrm{t}} \times H_{\mathrm{G}} \\
r_{\mathrm{t}}= & \frac{\pi}{24}(a+b \times \cos \omega) \\
& \times\left(\frac{\cos \omega-\cos \omega_{\mathrm{s}}}{\sin \omega_{\mathrm{s}}-\left(\pi \omega_{\mathrm{s}} / 180\right) \cos \omega_{\mathrm{s}}}\right)
\end{aligned}
$$

With: $a=0.4090-0.5016 \sin \left(\omega_{\mathrm{s}}+1.047\right)$

$b=0.6609+0.4767 \sin \left(\omega_{\mathrm{s}}+1.047\right)$.

VI. Estimation of monthly mean hourly diffuse solar irradiance on a horizontal surface [24]

$I_{\mathrm{D}}=r_{\mathrm{d}} \times H_{\mathrm{D}}$

$r_{\mathrm{d}}=\frac{\pi}{24}\left(\frac{\cos \omega-\cos \omega_{\mathrm{s}}}{\sin \omega_{\mathrm{s}}-\left(\pi \omega_{\mathrm{s}} / 180\right) \cos \omega_{\mathrm{s}}}\right)$.

VII. Estimation of monthly mean hourly direct solar irradiance on a horizontal surface

$I_{\mathrm{BH}}=I_{\mathrm{G}}-I_{\mathrm{D}}$.

VIII. Estimation of monthly mean hourly direct normal irradiance

$I_{\mathrm{BN}}=\frac{I_{\mathrm{BH}}}{\sin \delta \times \sin \varphi+\cos \delta \times \cos \varphi \times \cos \omega}$.
IX. Estimation of monthly mean daily direct normal irradiance

$H_{\mathrm{BN}}=\sum_{i=1}^{24} I_{\mathrm{BN}}(i) \times \Delta t$,

where $i$ is the time step, with $\Delta t=1 \mathrm{~h}$.

$\mathrm{X}$. Estimation of monthly direct normal irradiance

$\bar{H}_{\mathrm{BN}}=J(k) \times H_{\mathrm{BN}}(k)$,

where $J$ is the number of day for the $k$ month.

XI. Estimation of annual direct normal irradiance

$$
\overline{\bar{H}}_{\mathrm{BN}}=\sum_{k=1}^{12} \bar{H}_{\mathrm{BN}}(k) \text {. }
$$

\section{Comparison technique}

The prime purpose of this work is assessment of the proposed methodology for estimating the direct normal irradiance over three main Algerian ground stations (Algiers, Ghardaia, and Tamanrasset). For this, the validation of the obtained results by this methodology, in addition to that obtained by five spatial databases is carried out using nine statistical parameters: Mean Percent Error (MPE), Mean Absolute Percent Error (MAPE), Mean Bias Error (MBE), Mean Absolute Bias Error (MABE), Root Mean Square Error (RMSE), coefficient of determination $\left(R^{2}\right), t$ statistic method $\left(t_{\text {sta }}\right)$, and the Nash-Sutcliffe equation (NSE) for the validation of monthly values, and the percentage error $(e \%)$ for the validation of annual values. These performance indices are calculated using the following equations:

$\mathrm{MPE}=\frac{1}{n} \sum_{i=1}^{n}\left(\frac{Y_{i, \mathrm{~m}}-Y_{i, \mathrm{c}}}{Y_{i, \mathrm{~m}}}\right) 100$

MAPE $=\frac{1}{n} \sum_{i=1}^{n}\left(\left|\frac{Y_{i, \mathrm{~m}}-Y_{i, \mathrm{c}}}{Y_{i, \mathrm{~m}}}\right|\right) 100$

$\mathrm{MBE}=\frac{1}{n} \sum_{i=1}^{n}\left(Y_{i, \mathrm{~m}}-Y_{i, \mathrm{c}}\right)$

$\mathrm{MABE}=\frac{1}{n} \sum_{i=1}^{n}\left(\left|Y_{i, \mathrm{~m}}-Y_{i, \mathrm{c}}\right|\right)$

$\mathrm{RMSE}=\frac{1}{n} \sqrt{\sum_{i=1}^{n}\left(Y_{i, \mathrm{~m}}-Y_{i, \mathrm{c}}\right)^{2}}$

$R^{2}=\frac{\sum_{i=1}^{n}\left(Y_{i, \mathrm{~m}}-Y_{i, \mathrm{c}}\right)^{2}}{\sum_{i=1}^{n}\left(Y_{i, \mathrm{~m}}-\bar{Y}_{i, \mathrm{~m}}\right)^{2}}$

$t_{\mathrm{sta}}=\sqrt{\left[\frac{(n-1) \mathrm{MBE}^{2}}{\mathrm{RMSE}^{2}-\mathrm{MBE}^{2}}\right]}$ 
Table 2 Obtained annual DNI values of Algiers station $\left(\mathrm{kWh} / \mathrm{m}^{2}\right)$

\begin{tabular}{llllllllll}
\hline & Measured & Model 1 & Model 2 & Model 3 & NASA-SSE & Solar-Med-Atlas & SoDa (HC1) & SolarGIS & Meteonorm \\
\hline DNI annual values & 1,620 & 1,621 & 1,871 & 1,783 & 2,110 & 1,950 & 1,949 & 1,673 & 1,838 \\
$e(\%)$ & & 0.043 & 15.494 & 10.062 & 30.247 & 20.370 & 20.309 & 3.272 & 13.457 \\
\hline
\end{tabular}

Table 3 Obtained annual DNI values of Ghardaia station $\left(\mathrm{kWh} / \mathrm{m}^{2}\right)$

\begin{tabular}{llllllllll}
\hline & Measured & Model 1 & Model 2 & Model 3 & NASA-SSE & Solar-Med-Atlas & SoDa (HC1) & SolarGIS & Meteonorm \\
\hline DNI annual values & 2,419 & 2,409 & 2,610 & 2,083 & 2,405 & 2,377 & 2,481 & 2,104 & 2,815 \\
$e(\%)$ & & -0.406 & 7.923 & -13.863 & -0.563 & -1.730 & 2.600 & -13.005 & 16.389 \\
\hline
\end{tabular}

$\mathrm{NSE}=1-\frac{\sum_{i=1}^{n}\left(Y_{i, \mathrm{~m}}-Y_{i, \mathrm{c}}\right)^{2}}{\sum_{i=1}^{n}\left(Y_{i, \mathrm{~m}}-\bar{Y}_{i, \mathrm{~m}}\right)^{2}}$

$e(\%)=\frac{Y_{\mathrm{c}}-Y_{\mathrm{m}}}{Y_{\mathrm{m}}} \times 100$,

where $Y_{i, \mathrm{~m}}, Y_{i, \mathrm{c}}, \bar{Y}_{i, \mathrm{~m}}$ and $n$ are the measured values, calculated values, the average of the measured values, and the number of observations, respectively.

In this study, the results are compared on the basis of the nine above-mentioned statistical error tests, and the accuracy of the estimated data of the databases is determined using these tests. For better data modeling, the ideal values of statistical tests such as MPE, MAPE, MBE, MABE, RMSE, $t_{\text {sta }}$, NSE, and $e(\%)$ should be closer to zero, but $R^{2}$ should approach 1 as closely as possible [25].

\section{Results and discussion}

The methodology has been applied to estimate the monthly mean daily and annual values of the direct normal irradiance DNI for three main Algerian locations: Algiers, Ghardaia, and Tamanrasset; these stations have been selected because ground-based measurements of DNI are available and thus, the validation of the calculated values and those of spatial databases with measured ones can be made.

While the model 1 presents the calculated DNI data of the methodology in the presence of measured data of global and diffuse solar irradiance, the 2nd model shows the calculated data in the presence of measured global solar radiation and the absence of measured data of diffuse solar radiation. Moreover, the 3 rd and the last one calculate DNI in the absence of both global and diffuse measured data.

Tables 2, 3, and 4 show the resulting values of annual DNI and its percentage errors for Algiers, Ghardaia, and Tamanrasset, respectively, while Tables 5, 6, and 7 show the validation results of monthly mean daily DNI with the statistical parameters.
Algiers

As presented in Table 2, and for the results of the used methodology, it is reasonable that the annual DNI calculated for Algiers using the first model is the most accurate value $\left(1,621 \mathrm{kWh} / \mathrm{m}^{2}\right)$ with a percentage error of $0.043 \%$, and the worst one is that obtained by the second model $\left(1,871 \mathrm{kWh} / \mathrm{m}^{2}\right)$ that implies a percentage error of $15.494 \%$. While, the five spatial databases gave errors between $3.272 \%$ (SolarGIS) and $30.247 \%$ (NASA). Furthermore, as shown in Fig. 3 and Table 5, for the monthly mean daily values, the first model presents the highest coefficient of determination in the evaluation of the monthly mean daily DNI solar radiation as 0.977 , and gives the lowest values of the MPE, MAPE, MBE, MABE, RMSE, NSE, and $t_{\text {sta }}$ as 2.290, 6.439, 0.173, 0.322, 0.461, 0.893 , and 1.347 , respectively. While the worst results are derived by the SolarGIS database as $R^{2}=0.257$, $\mathrm{MPE}=48.167, \quad \mathrm{MAPE}=51.347, \quad \mathrm{MBE}=1.485$, $\mathrm{MABE}=1.697, \quad \mathrm{RMSE}=1.922, \quad \mathrm{NSE}=-0.865$, and $t_{\text {sta }}=4.036$ (Table 5).

\section{Ghardaia}

As shown in Table 3, the annual DNI calculated for Ghardaia using the first model of the methodology is the most accurate value $\left(2,409 \mathrm{kWh} / \mathrm{m}^{2}\right)$ with a percentage error of $-0.406 \%$, and the worst one is that obtained by the third model $\left(2,083 \mathrm{kWh} / \mathrm{m}^{2}\right)$ that implies a percentage error of $-13.863 \%$. While, the spatial databases gave errors between $-0.563 \%$ (NASA-SSE) and $16.389 \%$ (Meteonorm). Furthermore, as shown in Fig. 4 and Table 6, for the monthly mean daily values, the second model presents the highest coefficient of determination in the evaluation of the monthly mean daily DNI solar radiation as 0.952 , while the first model gives the lowest values of the MPE, MAPE, MBE, MABE, RMSE, NSE, and $t_{\text {sta }}$ as $0.153,4.805,-0.036,0.341,0.491,0.748$, and 0.243 , respectively. While the worst results is derived by the 
Table 4 Obtained annual DNI values of Tamanrasset station $\left(\mathrm{kWh} / \mathrm{m}^{2}\right)$

\begin{tabular}{llllllllll}
\hline & Measured & Model 1 & Model 2 & Model 3 & NASA-SSE & Solar-Med-Atlas & SoDa (HC1) & SolarGIS & Meteonorm \\
\hline DNI annual values & 2,658 & 2,665 & 2,753 & 2,098 & 2,480 & 2,758 & 2,631 & 2,428 & 2,719 \\
$e(\%)$ & & 0.261 & 3.56 & -21.079 & -6.709 & 3.613 & -1.029 & -8.665 & 2.281 \\
\hline
\end{tabular}

Table 5 Statistical error analyses of obtainedmonthly mean daily values for Algiers station

\begin{tabular}{llccccccc}
\hline Parameter & Model 1 & Model 2 & Model 3 & NASA-SSE & Solar-Med-Atlas & SoDa (HC1) & SolarGIS & Meteonorm \\
\hline MPE & 2.290 & 30.066 & 30.474 & 40.354 & 40.730 & 37.918 & 48.167 & 23.616 \\
MAPE & 6.439 & 30.066 & 30.569 & 40.354 & 40.730 & 37.918 & 51.347 & 24.893 \\
MBE & 0.173 & 1.250 & 0.978 & 1.514 & 1.493 & 1.468 & 1.485 \\
MABE & 0.322 & 1.250 & 0.985 & 1.514 & 1.493 & 1.468 & 0.768 \\
RMSE & 0.461 & 1.322 & 1.158 & 1.599 & 1.636 & 1.712 & 1.697 \\
$R^{2}$ & 0.977 & 0.974 & 0.896 & 0.868 & 0.778 & 0.732 & 0.828 \\
NSE & 0.893 & 0.119 & 0.324 & -0.291 & -0.350 & -0.479 & -0.865 \\
$t_{\text {sta }}$ & 1.347 & 9.663 & 5.246 & 9.746 & 7.425 & 5.524 & 0.960 \\
\hline
\end{tabular}

Table 6 Statistical error analyses of obtained monthly mean daily values for Ghardaia station

\begin{tabular}{lrlrrrrrr}
\hline Parameter & Model 1 & Model 2 & Model 3 & NASA-SSE & Solar-Med-Atlas & SoDa (HC1) & SolarGIS & Meteonorm \\
\hline MPE & 0.153 & 7.983 & -13.493 & 0.339 & -0.976 & 3.481 & -11.892 & 18.094 \\
MAPE & 4.805 & 7.983 & 13.493 & 24.039 & 12.736 & 17.486 & 16.563 & 20.477 \\
MBE & -0.036 & 0.528 & -0.920 & -0.059 & -0.123 & 0.157 & -0.878 \\
MABE & 0.341 & 0.528 & 0.920 & 1.534 & 0.802 & 1.128 & 1.063 \\
RMSE & 0.491 & 0.577 & 1.073 & 1.835 & 1.001 & 1.333 & 1.265 \\
$R^{2}$ & 0.773 & 0.952 & 0.683 & 0.051 & 0.295 & 0.129 & 1.244 \\
NSE & 0.748 & 0.652 & -0.201 & -2.517 & -0.046 & -0.855 & 0.211 \\
$t_{\text {sta }}$ & 0.243 & 7.470 & 5.532 & 0.107 & 0.412 & 0.393 & -0.616 & -1.494 \\
\hline
\end{tabular}

Table 7 Statistical error analyses of obtained monthly mean daily values for Tamanrasset station

\begin{tabular}{lllllllll}
\hline Parameter & Model 1 & Model 2 & Model 3 & NASA-SSE & Solar-Med-Atlas & SoDa (HC1) & SolarGIS & Meteonorm \\
\hline MPE & 1.061 & 12.479 & -13.192 & -4.792 & 13.829 & 8.111 & -8.044 & 4.041 \\
MAPE & 4.986 & 12.479 & 15.022 & 14.356 & 15.196 & 13.387 & 8.044 \\
MBE & 0.006 & 0.860 & -1.100 & -0.498 & 0.884 & 0.503 & -0.623 \\
MABE & 0.379 & 0.860 & 1.210 & 1.087 & 1.008 & 0.948 & 0.146 \\
RMSE & 0.586 & 0.969 & 1.574 & 1.299 & 1.301 & 1.190 & 0.815 \\
$R^{2}$ & 0.846 & 0.646 & 0.046 & 0.033 & 0.329 & 0.298 & 0.816 \\
NSE & 0.741 & 0.292 & -0.867 & -0.273 & -0.277 & -0.068 & 0.500 & 0.040 \\
$t_{\text {sta }}$ & 0.033 & 6.390 & 3.241 & 1.377 & 3.071 & 1.548 & 3.931 & 0.393 \\
\hline
\end{tabular}

NASA database as $R^{2}=0.051, \mathrm{MPE}=0.339, \mathrm{MAPE}=$ 24.039, $\quad \mathrm{MBE}=-0.059, \quad \mathrm{MABE}=1.534, \quad \mathrm{RMSE}=$ $1.835, \mathrm{NSE}=-2.517$, and $t_{\mathrm{sta}}=0.107$.

Tamanrasset

As presented in Table 4, it is reasonable that the different spatial databases used in this study gave good results for the monthly and annual DNI values because Tamanrasset's ground station is included in these databases as a station for interpolation.

Using the first model gives the most accurate value $\left(2,665 \mathrm{kWh} / \mathrm{m}^{2}\right)$ with a percentage error of $0.261 \%$, and the worst value is that obtained by the third model $\left(2,098 \mathrm{kWh} / \mathrm{m}^{2}\right)$ that implies a percentage error of $21.079 \%$. While, the five spatial databases gave errors 


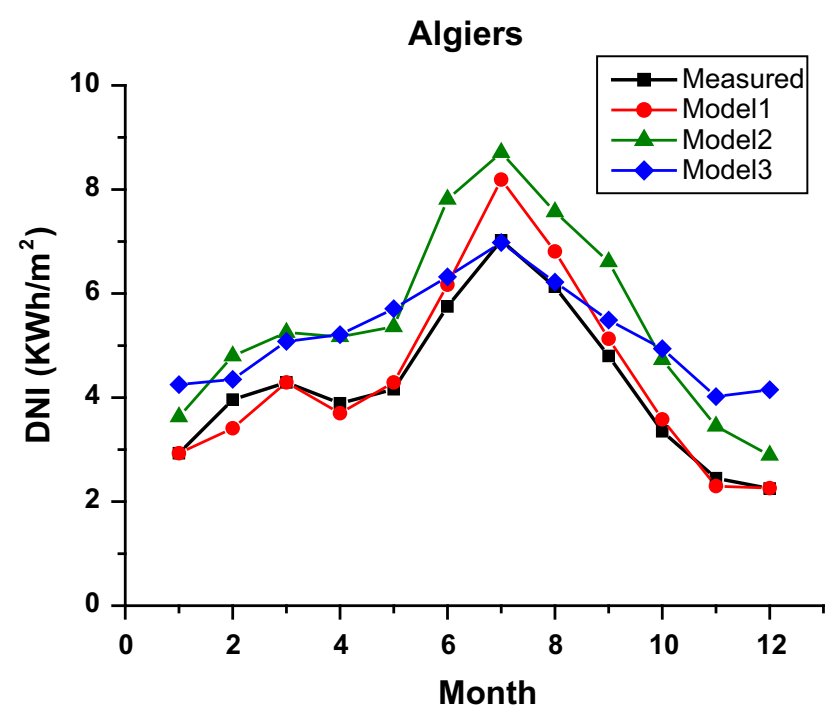

Fig. 3 Obtained monthly mean daily values by the proposed methodology for Algiers station

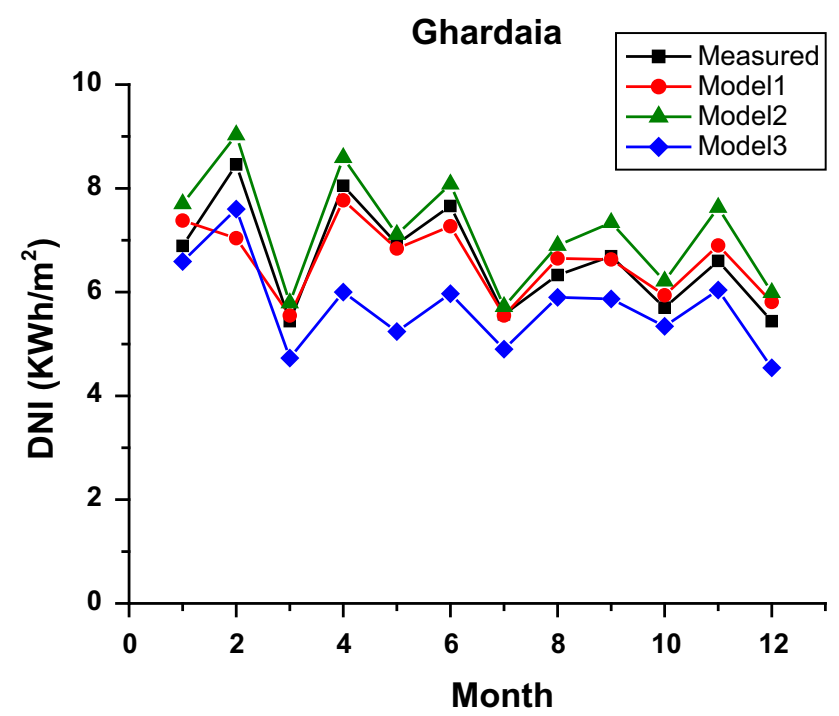

Fig. 4 Obtained monthly mean daily values by the proposed methodology for Ghardaiastation

between $-1.029 \%$ (SoDa) and $-8.665 \%$ (SolarGIS). While, the monthly mean daily values, and as shown in Fig. 5 and Table 7, the first model presents the highest coefficient of determination in the evaluation of the monthly mean daily DNI solar radiation as 0.846 , and gives the lowest values of the MPE, MAPE, MBE, MABE, RMSE, NSE, and $t_{\text {sta }}$ as 1.061, 4.986, 0.006, 0.379, 0.586, 0.741 , and 0.033 , respectively. While the worst results is derived by the third model as $R^{2}=0.046, \mathrm{MPE}=-$ 13.192, $\quad$ MAPE $=15.022, \quad \mathrm{MBE}=-1.100, \quad \mathrm{MABE}=$ $1.210, \mathrm{RMSE}=1.574, \mathrm{NSE}=-0.867$, and $t_{\mathrm{sta}}=3.241$.

In conclusion, the monthly mean daily and annual DNI values produced by the first model of the proposed
Tamanrasset

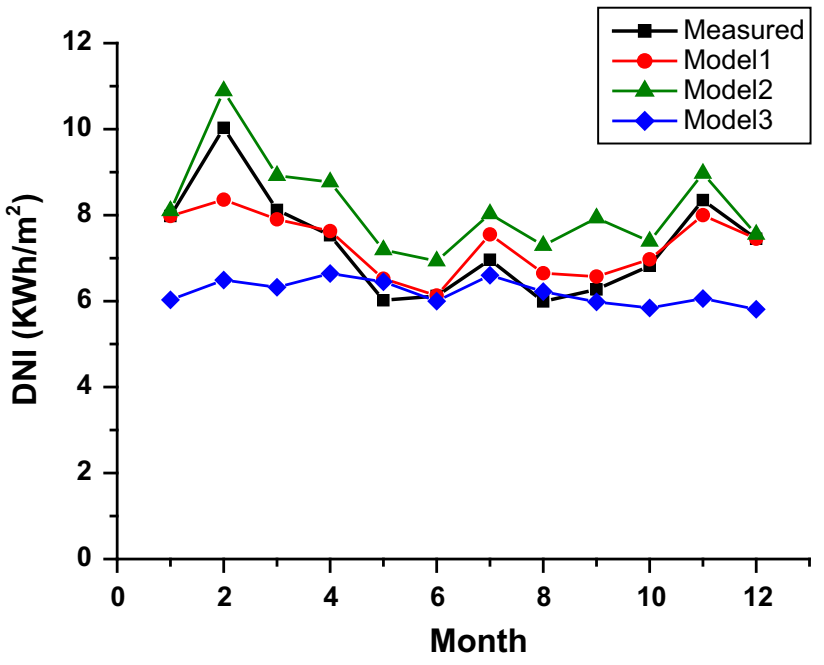

Fig. 5 Obtained monthly mean daily values by the proposed methodology for Tamanrassetstation

methodology are excellent according to the measured ones. Indeed, in case of availability of measured values of global and diffuse horizontal irradiance, it is recommended to use this model to estimate DNI. Furthermore, the results of the two other models are comparable to those of the spatial databases, thus, it can be used to compute DNI for the three Algerian stations.

\section{Conclusion}

In the present study, we have proposed a methodology for estimating the hourly, monthly mean daily, and annual direct normal irradiance DNI in the presence or the absence of measured global and diffuse horizontal irradiances. When applying the proposed method for calculation of DNI for three Algerian ground stations (Algiers, Ghardaia, and Tamanrasset), we obtained better performances than those of the five spatial databases' data, especially for monthly values of DNI. The methodology seems to give a very appropriate way for the management and exploitation of DNI resources for the design and analysis of CPV and CSP systems; it is easy to be implemented and uses simple equations. Future actions will include the application of the methodology to other worldwide locations using empirical equations with new correlation coefficients for estimating direct normal irradiance.

Conflict of interest The authors declare that they have no competing interests.

Authors' contributions MMS co-supervised the work and corrected the draft manuscript. All authors read and approved the final 
manuscript.BTE co-supervised the work, collected the references and the informations, and drafted the manuscript. While NEB made the calculations.

Open Access This article is distributed under the terms of the Creative Commons Attribution License which permits any use, distribution, and reproduction in any medium, provided the original author(s) and the source are credited.

\section{References}

1. Stambouli, A.B., Khiat, Z., Flazi, S., Kitamura, Y.: A review on the renewable energy development in Algeria: current perspective, energy scenario and sustainability issues. Renew. Sust. Energy. Rev. 16(7), 4445-4460 (2012)

2. Boukelia, T.E., Mecibah, M.S.: Parabolic trough solar thermal power plant: potential, and projects development in Algeria. Renew. Sust. Energy. Rev. 21, 288-297 (2013)

3. Boukelia, T.E., Mecibah, M.S.: Solid waste as renewable source of energy: current and future possibility in Algeria. Int. J. Energy Environ. Eng. 3, 1-12 (2012)

4. Sonelgaz Group Company: Renewable energy and energy efficiency program. Ministry of Energy and Mines. http://www. mem-algeria.org. Accessed March 2013

5. Stoffel, T, Renne, D, Myers, D, Wilcox, S, Sergupta, M, George, R, Turchi, C: Concentrating solar power: best practices handbook for the collection and use of solar resource data. Technical Report NREL/TP-550 -47465, pp. 146. September, 2010 http://www. nrel.gov/docs/fy10osti/47465.pdf

6. Myers, D: Comparison of historical satellite based estimates of solar radiation resources with recent rotating shadow band radiometer measurements. American Solar Energy Society Proceedings, May12-15, http://www.nrel.gov/docs/fy09osti/45375.pdf. (2009)

7. Vick, B.D., Myers, D.R., Boyson, W.E.: Using direct normal irradiance models and utility electrical loading to assess benefit of a concentrating solar power plant. Sol. Energy 86(12), 3519-3530 (2012)

8. Hoyer-Klick, C, et al.: MESoR-Management and exploitation of solar resorce knowledge. In Solar Paces (2009)

9. Atmospheric Science Datacenter. NASA surface meteorology and solar energy-location. https://eosweb.larc.nasa.gov/sse/. Accessed March 2013

10. Mines ParisTech. SoDa: Solar radiation data. http://www.soda-is. com/eng/index.html. Accessed March 2013.

11. Meteonorm. Meteonorm: Global Meteorological Database. http:// meteonorm.com/. Accessed March 2013

12. Pagola, I., Gastón, M., Fernández-Peruchena, C., Moreno, S., Ramírez, L.: New methodology of solar radiation evaluation using free access databases in specific locations. Renew. Energy. 35(12), 2792-2798 (2010)

13. Pérez-Higueras, P.J., Rodrigo, P., Fernández, E.F., Almonacid, F., Hontoria, L.: A simplified method for estimating direct normal solar irradiation from global horizontal irradiation useful for CPV applications. Renew. Sust. Energy. Rev. 16(8), 5529-5534 (2012)

14. Solanki, C.S., Sangani, C.S.: Estimation of monthly averaged direct normal solar radiation using elevation angle for any location. Sol. Energy Mater. Sol. Cells 92(1), 38-44 (2008)

15. Solar-Med-Atlas. Solar Atlas for the Mediterranean. http://www. solar-med-atlas.org/. Accessed March 2013

16. SolarGIS. SolarGIS. http://solargis.info/. Accessed March 2013

17. Centre of Development of Renewable energies. http://www.cder. dz/. Accessed March 2013

18. Suri, M, et al.: Comparison of direct normal irradiation maps for Europe. In Solar Paces (2009)

19. Badescu, V.: Modeling solar radiation at the earth surface. Recent advances. Springer, Berlin (2008)

20. Duffie, J.A., Beckman, W.A.: Solar engineering of thermal processes, 2nd edn. Wiley, New York (1992)

21. Mecibah, M.S., Boukelia, T.E., Tahtah, R., Gairaa, K.: Introducing the best model for estimation the monthly mean daily global solar radiation on a horizontal surface (Case study: Algeria). Renew. Sust. Energy Rev. 36, 194-202 (2014)

22. Boukelia, T.E., Mecibah, M.S., Meriche, I.E.: General models for estimation of the monthly mean daily diffuse solar radiation (Case study: Algeria). Energy Convers. Manage. 81, 211-219 (2014)

23. Collares-Pereira, M., Rabl, A.: The average distribution of solar radiation correlations between Diffuse and hemispherical and BETWEEN daily and hourly insolation values. Sol. Energy 22(2), 155-164 (1979)

24. Liu, B., Jordan, R.: The interrelationship and characteristic distribution of direct, Diffuse and total solar radiation. Sol. Energy 4(3), 1-19 (1960)

25. Duzen, H., Aydin, H.: Sunshine-based estimation of global solar radiation on horizontal surface at Lake Van Region (Turkey). Energy Convers. Manage. 58, 35-46 (2012)

Mohamed Salah Mecibah is a lecturer at Constantine 1 University (Algeria). He received his Ph.D. degree in Mechanical Engineering from Mentouri Constantine University, in 2010.

Taqiy Eddine Boukelia received his master's degree in Mechanical Engineering in 2011 from the University of Mentouriin Algeria, and he started his doctorate in the same year. He has been interested in renewable energies field.

Nour Eddine Benyahia is currently a $\mathrm{PhD}$ student in University of Constantine 1. 